\title{
Quantitation of Fat Soluble Vitamins in Different Walnut Genotypes and Commercial Cultivars; a Comprehensive and Robust LC-MS/MS Method Validation
}

\author{
Mustafa Abdullah YILMAZ ${ }^{1^{*}}$
}

\begin{abstract}
Walnut, being both nutritious and delicious, has been regarded as a health food due to its preventive and therapeutic effects. In the present study, a robust LC-MS/MS analytical method was developed to simultaneously quantify five fat soluble vitamins $\left(\mathrm{D}_{2}, \mathrm{D}_{3}, \mathrm{~K}_{2}, \mathrm{E}, \mathrm{K}_{1}\right)$ in eleven walnut genotypes and two commercial cultivars. Linearity, accuracy, inter- and intra-day precision, detection limit (LOD), quantification limit (LOQ) and uncertainty ( $\mathrm{U}$ at confidence level of $95 \%(\mathrm{k}=2)$ ) were the validation parameters of the developed LC-MS/MS method. The established linearity ranges for the studied vitamins were between 50 and $1200 \mathrm{mg} \mathrm{L}^{-1}$ for vitamins $\mathrm{D}_{2}, \mathrm{D}_{3}, \mathrm{~K}_{1}$, between 100-2400 $\mathrm{mgL}^{-1}$ for vitamin $\mathrm{E}$ and between $200-4800 \mathrm{mg} \mathrm{L}^{-1}$ for vitamin $\mathrm{K}_{2}$. The coefficients of determination for the vitamins $\mathrm{D}_{2}, \mathrm{D}_{3}, \mathrm{~K}_{2}$, E, $\mathrm{K}_{1}$ were between 0.9990, 0.9991, 0.9995, 0.9997, 0.9991, respectively. Vitamins $\mathrm{D}_{3}, \mathrm{~K}_{2}$ and $\mathrm{K}_{1}$ were not present in the analysed walnut samples. On the other hand, vitamins $E$ and $D_{2}$ were in high quantities in all studied walnut samples. $D_{2}$ and $E$ were the most abundant fat soluble vitamins in MDE32 (29.1 $\mathrm{mg} \mathrm{g}^{-1}$ dry plant) and MDE5 (15.2 $\mathrm{mg} \mathrm{g}^{-1}$ dry plant) genotypes. Despite the fact that the walnut was selected as real life sample, the validated LC-MS/MS method is enforceable to a broad range of food species.
\end{abstract}

Keywords: Fat soluble vitamins, analytical method validation, LC-MS/MS, walnut.

\footnotetext{
${ }^{1}$ Mustafa Abdullah YILMAZ (Orcid ID: 0000-0002-4090-7227), Department of Pharmaceutical Chemistry, Faculity of Pharmacy, Dicle University, Diyarbakir, Turkey

* Sorumlu Yazar/Corresponding Author: Mustafa Abdullah YILMAZ, e-mail: mustafaabdullahyilmaz@gmail.com 


\section{INTRODUCTION}

Being the most prevalent tree nut throughout the world, walnut global production has ramped from $1.6 \times 10^{6}$ tons (2004) up to $3.5 \times 10^{6}$ tons $(2014)(\mathrm{FAO}, 2018)$. Although its origin is central Asia, cultivation of walnut has latterly reached lands as far as Mexico, Egypt, Ukraine, Romaine or France. Nevertheless, Turkey, Iran, US and China are still the main production countries (FAO, 2018). The improvement of novel walnut genotypes has been innervated by the agriculture of walnut tree in the mentioned different places, their adaption to the environment of cultivating area and the local markets' predilection. Those cultivars embody an enormous genetic inventory of the species that ought to be studied with the aim to understand their particular features and make the most of it.

The interest in walnut consumption and production depends on the health promotion characteristics of the walnut. Consumption of walnut builds up the lipoprotein profile in blood, demonstrates antiatherogenic and anticancer effects, conduces to the adjustment of inflammatory activity and response immunological activity (Yang et al., 2009; Awad and Fink, 2000). Furthermore, walnut consumption isn't affiliated with weight rise (Ibarrola-Jurado et al., 2013). The positive benefits of walnuts in lowering blood cholesterol should not be ignored (Fraser et al., 1992). One reason for these advantages is the tocopherol content of walnut. Experiments have shown that certain foods such as nuts reduces low density lipoprotein and total plasma cholesterol, which in turn reduces the potential risk of coronary heart disease. (Sabaté et al., 1993; Abbey et al., 1994).

Walnut is evaluated as a fine vitamin $\mathrm{E}$ source, with tocopherol concentrations betwixt
194 and $297 \mu \mathrm{g} / \mathrm{g}$ (Amaral et al., 2005). Alpha and delta tocopherols are the main ones detected in walnut oil (Crews et al., 2005; Martínez et al., 2006), while high concentration of $\gamma$-tocopherol has been found in partly defatted flours (Santos et al., 2017). Mentioned fat-soluble molecules take part in pivotal functions, acting not only as antioxidants but also as membrane stabilizers (Amaral et al., 2005).

Taking into account the nutritional importance of walnuts and important role of fat soluble vitamins, investigating their content in walnuts is of great importance. Nevertheless, the complex and labile ingredients of walnuts have created hassles for detection methods used to determine its vitamin content. Vitamins in nuts have been investigated by various analytical techniques such as UV-Vis, GC-MS, HPLC and LC-MS/MS (Rabadán et al., 2018; Bakkalbaşı et al., 2012; Stuetz et al., 2017;

In the present study, the development and validatation of a comprehensive and robust LCMS/MS method was aimed for simultaneous and quantitative determination of five fat soluble vitamins $\left(\mathrm{D}_{2}, \mathrm{D}_{3}, \mathrm{~K}_{2}, \mathrm{E}, \mathrm{K}_{1}\right)$ in eleven walnut genotypes and two commercial cultivars.

\section{MATERIALS and METHODS}

\section{Chemicals and Standard Solutions}

Reference standards of fat soluble vitamin A acetate (used as internal standard), vitamin $\mathrm{D}_{2}$ (99.7\%), vitamin $\mathrm{D}_{3} \quad(98.9 \%)$, vitamin $\mathrm{K}_{2}(100 \%)$, vitamin $\mathrm{E}(99.5 \%)$ and vitamin $\mathrm{K}_{1}(97.7 \%)$ were obtained from Dr. Ehrenstorfer (Augsburg, Germany). Formic acid, hexane and chromatographic grade methanol were obtained from Merck (Darmstadt, Germany). Type 1 pure water was acquired from Sartorious (Goettingen, Germany) Arium ro Ultrapure Water System. 
<smiles>CC(=O)OC/C=C(C)/C=C/C=C(C)/C=C/C1=C(C)CCCC1(C)C</smiles>

\section{Vitamin A Acetate}<smiles>C=C1CC[C@H](O)C/C1=C/C=C1\CCC[C@]2(C)C1CC[C@H]2[C@H](C)/C=C/[C@H](C)C(C)C</smiles>

Vitamin $\mathrm{D}_{2}$<smiles>C=C1CC[C@H](O)C/C1=C/C=C1\CCC[C@]2(C)C1CC[C@H]2[C@H](C)CCCC(C)C</smiles>

Vitamin $\mathrm{D}_{3}$<smiles>CC1=C(C/C=C(\C)CCCC(C)CCCC(C)CCCC(C)C)C(=O)c2ccccc2C1=O</smiles>

Vitamin $\mathrm{K}_{1}$<smiles>CC(C)=CCC/C(C)=C/CC/C(C)=C/CC/C(C)=C/CC1=C(C)C(=O)c2ccccc2C1=O</smiles>

Vitamin $\mathrm{K}_{2}$<smiles>Cc1c(C)c2c(c(C)c1O)CC[C@@](C)(CCC[C@H](C)CCC[C@H](C)CCCC(C)C)O2</smiles>

Vitamin E

Figure 1. Molecular structures of the vitamin standards used in the LC-MS/MS method

Main stock solutions of vitamin A acetate (2000 mg L $\left.{ }^{-1}-\mathrm{IS}\right)$, vitamin $\mathrm{D}_{2}\left(80 \mathrm{mg} \mathrm{L}^{-1}\right)$, vitamin $\mathrm{D}_{3}\left(80 \mathrm{mg} \mathrm{L}^{-1}\right)$, vitamin $\mathrm{K}_{2}(320 \mathrm{mg}$ $\left.\mathrm{L}^{-1}\right)$, vitamin $\mathrm{E}\left(160 \mathrm{mg} \mathrm{L}^{-1}\right)$ and vitamin $\mathrm{K}_{1}(80$ $\mathrm{mg} \mathrm{L}^{-1}$ ) were prepared from their purchased standards (Figure 1). The prepared standard solutions were kept at $-20^{\circ} \mathrm{C}$ until to be studied. Then, solutions for the calibration points were got ready by diluting the standard stock solutions. Each calibration point and sample solutions were spiked with $50 \mu \mathrm{L}$ of $5 \mathrm{mg} \mathrm{L}^{-} 1$ internal standard solution in order its concentration to be $250 \mu \mathrm{g} / \mathrm{L}$.

\section{Plant material}

Eleven walnut genotypes (MDE2, MDE5, MDE18, MDE24, MDE32, MDE39, MDE42, MDE45, MDE50, MDE56, MDE67) were selected from the Derik district of Mardin province in the Southeast part of Turkey in 2014 and two walnut cultivars (Chandler and Franquette) were collected from commercial plantations of Sanliurfa province, Southeast Turkey. To determine their fat soluble vitamins in their fruits, walnut samples were immediately dried and stored in their shells at room temperature until analysis. 


\section{Extraction of walnuts for LC-MS/MS}

The air dried walnut fruits were removed from their shells. Afterwards, they were grounded and 0.25 grams of the fruit samples were placed in a $15 \mathrm{~mL}$ centrifuge tube. Then 50 $\mu \mathrm{L}$ of $5 \mathrm{mg} \mathrm{L}^{-1}$ internal standard solution was added to the sample. Then, $1.5 \mathrm{~mL}$ water and 1.5 $\mathrm{mL}$ methanol were put in and the mixture was shaken vigorously for $1 \mathrm{~min}$. The centrifuge tube containing the mixture was kept in the ultrasonic bath for 15 minutes. Then, the tube was filled up to $10 \mathrm{~mL}$ with hexane. The mixture was shaken for 5 minutes. Then the mixture was centrifuged for 10 minutes $(4400 \mathrm{rpm})$. Then, $1 \mathrm{~mL}$ of the supernatant was put into a glass tube and the solvents were evaporated under $\mathrm{N}_{2}$ gas stream. The extract was dissolved in $1 \mathrm{~mL}$ of methanol and fitlered through $0,2 \mu \mathrm{m}$ syringe filter stored in the fridge $\left(-20{ }^{\circ} \mathrm{C}\right)$ prior to LC-MS/MS analysis.

\section{LC-MS Instrumentation chtomatographic conditions}

Quantiative investigation of five fat soluble vitamins was performed by using a Nexera model Shimadzu-UHPLC combined with an LCMS 8040 model tandem mass spectrometer. The equipment of the liquid chromatograph was; SIL-30AC autosampler, DGU- 20A3R degasser, CTO-10ASvp column oven and LC-30AD binary pumps. The chromatographic seperation was carried out with a Restek Ultra PFPP $(150 \mathrm{~mm} \times 4.6 \mathrm{~mm}, 5 \mu \mathrm{m})$ column. Reversed-phase liquid chromatograph was optimized to achive satisfactory separation of the vitamins under study. Temperature of the column was fixed at $25{ }^{\circ} \mathrm{C}$. The elution gradient comprised mobile phase A (water, $0.15 \%$ formic acid) and mobile phase B (methanol, 0.15 $\%$ formic acid). The following gradient program was applied: $80-100 \% \mathrm{~B}$ (0-20 $\mathrm{min}), 100 \% \mathrm{~B}$ (20-25 min), $80 \%$ B (25-30 min). Flow rate of the solvent and the injection volume was optimized as $0.6 \mathrm{~mL} / \mathrm{min}$ and $1 \mu \mathrm{L}$, respectively.

The triple quadrupole mass spectrometer was equipped with an electrospray ionization (ESI) source that operated in positive mode. LabSolutions software (Shimadzu) was used for LC- MS/MS data processing. The multiple reaction monitoring (MRM) mode was applied to quantify the vitamins under study following two or three transitions per compound, first one to quantify and the latter to qualify. The mass spectrometer operating conditions were determined as DL temperature, $250{ }^{\circ} \mathrm{C}$; heat block temperature, $400{ }^{\circ} \mathrm{C}$; interface temperature, $350{ }^{\circ} \mathrm{C}$; drying gas flow (nitrogen); $15 \mathrm{~L} / \mathrm{min}$ and nebulizing gas flow (nitrogen), 3 $\mathrm{L} / \mathrm{min}$.

\section{LC-MS/MS analytical method validation studies}

In this study, validation and development of a robust and comprehensive LC-MS/MS method was carried out for the quantification of five fat soluble vitamins $\left(D_{2}, D_{3}, K_{2}, E, K_{1}\right)$ in eleven walnut genotypes and two commercial cultivars. The performance fatures of the analytical method were established by using internal and external standard solutions, spiked and non-spiked samples. Within this in mind, the developed LC-MS/MS method was validated in terms of linearity, limits of detection and quantification (LOD/LOQ), inter-day and intraday precision (repeatability), accuracy (recovery) and relative standard uncertainty (U\% at $95 \%$ confidence level $(\mathrm{k}=2))$. The validation parameters of the LC-MS/MS method were given in Table 1. 


\section{RESULTS AND DISCUSSION}

\section{Linearity}

The linearities of the analytes were determined by using internal standard calibration with eight concentration levels for each vitamin analyte, and each concentration level was analyzed in triplicate. Internal standard was used to correct the the analyte loss during sample preparation. The developed method determined to be linear for the studied vitamins. The correlation coefficients for the vitamins $\mathrm{D}_{2}, \mathrm{D}_{3}$, $\mathrm{K}_{2}, \mathrm{E}, \mathrm{K}_{1}$, between the ranges of tested concentrations were 0.9990, 0.9991, 0.9995, 0.9997, 0.9991, respectively. The linear regression equations of the calibration curves were shown in Table 1.

Table 1. Analytical parameters belong to the validated LC-MS/MS method ( ${ }^{\mathrm{a}} \mathrm{RT}$ : Retention time (min), ${ }^{\mathrm{b}}$ Mother ion $(\mathrm{m} / \mathrm{z})$ : Parent ions of the vitamin compounds ( $\mathrm{m} / \mathrm{z}$ ratio), ${ }^{\mathrm{c}} \mathrm{R}^{2}$ : Coefficient of determination, ${ }^{\mathrm{d}} \mathrm{RSD}$ : Relative standard deviation, ${ }^{\mathrm{e}} \mathrm{LOD} / \mathrm{LOQ}\left(\mu \mathrm{gL}^{-1}\right)$ : Limits of detection andquantification, ${ }^{\mathrm{f}} \mathrm{U}(\%)$ :percent relative uncertainty at $95 \%$ confidence level $(\mathrm{k}=2),{ }^{\mathrm{g}}$ IS: Internal Standard $)$

\begin{tabular}{|c|c|c|c|c|c|c|c|c|c|c|c|c|c|c|}
\hline \multirow{2}{*}{ No } & \multirow{2}{*}{ Analytes } & \multirow{2}{*}{$\mathbf{R T}^{\mathbf{a}}$} & \multirow{2}{*}{$\begin{array}{l}\text { Mother } \\
\text { ion } \\
(\mathbf{m} / \mathbf{z})^{\mathbf{b}}\end{array}$} & \multirow{2}{*}{ Daughter ions } & \multirow{2}{*}{$\begin{array}{l}\text { Ion. } \\
\text { mode }\end{array}$} & \multirow{2}{*}{ Equation } & \multirow{2}{*}{$\mathbf{R}^{2 \mathrm{c}}$} & \multicolumn{2}{|c|}{ RSD $\%^{d}$} & \multirow{2}{*}{$\begin{array}{l}\text { Linearity } \\
\text { Range } \\
\left(\mu \mathrm{g} \mathrm{L}^{-1}\right)\end{array}$} & \multirow{2}{*}{$\begin{array}{l}\mathrm{LOD} / \mathrm{LOQ} \\
\left.(\mu \mathrm{g} \mathrm{L})^{-1}\right)^{\mathrm{e}}\end{array}$} & \multicolumn{2}{|c|}{ Recovery (\%) } & \multirow{2}{*}{$\mathbf{U}^{\mathrm{f}}$} \\
\hline & & & & & & & & Interday & Intraday & & & Interday & Intraday & \\
\hline 1 & $\begin{array}{l}\text { Vitamin A } \\
\text { acetate (IS) }\end{array}$ & 12.9 & 329.3 & $269.3 / 254.3 / 145.2$ & Poz & - & & - & & - & - & - & - & - \\
\hline 2 & Vitamin $D_{2}$ & 13.9 & 397.5 & 69.2/107.2/105.0 & Poz & $y=1422000 x+38095.6$ & 0.9990 & 0.0247 & 0.0364 & $50-1200$ & $5.3 / 17.7$ & 0.9943 & 1.0195 & 0.075 \\
\hline 3 & Vitamin $D_{3}$ & 14.0 & 385.5 & $259.4 / 367.4 / 107.1$ & Poz & $y=821541 x+20012.6$ & 0.9991 & 0.0187 & 0.0215 & $50-1200$ & $10.1 / 33.7$ & 1.0132 & 1.0323 & 0.089 \\
\hline 4 & Vitamin $\mathrm{K}_{2}$ & 17.9 & 445.4 & $187.2 / 227.0$ & Poz & $y=215092 x+9826.5$ & 0.9995 & 0.0353 & 0.0512 & $200-4800$ & $25.6 / 85.3$ & 1.0213 & 1.0451 & 0.204 \\
\hline 5 & Vitamin E & 18.0 & 431.5 & $165.2 / 137.2$ & Poz & $y=122530 x+19271.7$ & 0.9997 & 0.0182 & 0.0388 & $100-2400$ & $8.3 / 27.7$ & 1.0254 & 1.0568 & 0.164 \\
\hline 6 & Vitamin $\mathrm{K}_{1}$ & 20.4 & 451.5 & $187.2 / 185.0$ & Poz & $y=431340 x+7885.3$ & 0.9991 & 0.0546 & 0.0763 & $50-1200$ & $6.4 / 21.3$ & 1.0342 & 1.0587 & 0.097 \\
\hline
\end{tabular}

\section{Accuracy (recovery) and precision (repeatability)}

Precision and accuracy studies of the developed method were carried out by standard addition to a chosen walnut sample. For intraday precision evaluation, fortified samples were analyzed for six replicates within a single day, whereas fortified samples were examined in six replicates per day for three consecutive days to conduct inter-day precision assay. As a result of the intra-day and inter-day studies, RSD \% and recovery values were used to assess the precision and accuracy (Table 1).The following equation was used to calculate the recovery: recovery (\%) $=$ (detected concentration - original concentration)/spiked concentration $\times 100$. Interday/intraday RSD \% values were determined to be $0.0247 / 0.0364,0.0187 / 0.0215$, $0.0353 / 0.512,0.0182 / 0.0388$ and $0.0546 / 0.0763$ for vitamins $D_{2}, D_{3}, K_{2}, E$ and $K_{1}$, respectively. As for recovery studies, the measured percent recoveries were found to be $0.9943 / 1.0195$, $1.0132 / 1.0323,1.0213 / 1.0451,1.0254 / 1.0568$ and $1.0342 / 1.0587$ for vitamins $\mathrm{D}_{2}, \mathrm{D}_{3}, \mathrm{~K}_{2}, \mathrm{E}$ and $\mathrm{K}_{1}$, respectively. 


\section{Limits of detection and quantification (LOD/LOQ)}

To evaluate the LOD and LOQ values for the vitamin compounds used, ten identical solutions that contains the lowest concentration signaled by each vitamin standard were prepared and injected to the instrument. The determined limits of detection and quantification values for the studied analytes were as; 5.3/17.7, 10.1/33.7, 25.6/85.3, 8.3/27.7 and 6.4/21.3 for vitamins $D_{2}$, $\mathrm{D}_{3}, \mathrm{~K}_{2}, \mathrm{E}$ and $\mathrm{K}_{1}$, respectively. LOD and LOQ values were reckoned by the following equations (Equations 1 and 2):

$$
\begin{aligned}
& \mathrm{LOD}=\text { Mean }+3 \times \text { Standard Deviation } \\
& \mathrm{LOQ}=\text { Mean }+10 \times \text { Standard Deviation }
\end{aligned}
$$

\section{Standard relative uncertainty $\left(\mathrm{U}^{95}\right)$}

Standard uncertainties of the analytes were determined by the precision and accuracy studies in agreement with the EURACHEM Guide (EURACHEM CITAC Guide, 2004).

\section{Simultaneous quantitation of WSVs in walnut samples by LC-MS/MS}

The developed and validated LC-MS/MS method was applied to simultaneously quantify five fat soluble vitamins (vitamins $\mathrm{D}_{2}, \mathrm{D}_{3}, \mathrm{~K}_{2}, \mathrm{E}$ and $\mathrm{K}_{1}$ ) in eleven walnut genotypes (MDE2, MDE5, MDE18, MDE24, MDE32, MDE39, MDE42, MDE45, MDE50, MDE56, MDE67) and two commercial walnut cultivars (Chandler and Franqueete) from the Southeast part of Turkey. According to the quantitative results of the LC-MS/MS analysis, amounts of vitamin $\mathrm{D}_{2}$ and vitamin $\mathrm{E}$ found to be quite high in the studied genoypes and commercial cultivars of walnut samples. However, other studied vitamins $\left(\mathrm{D}_{3}, \mathrm{~K}_{2}\right.$ and $\left.\mathrm{K}_{1}\right)$ were not present in any of the walnut samples (Table 2). Figure 2 and Figure 3 shows the TIC chromatogram for the LC-MS/MS analysis of vitamin standards and MDE 2 genotype. Figure 4 shows the LCMS/MS TIC chromatograms of other walnut samples.

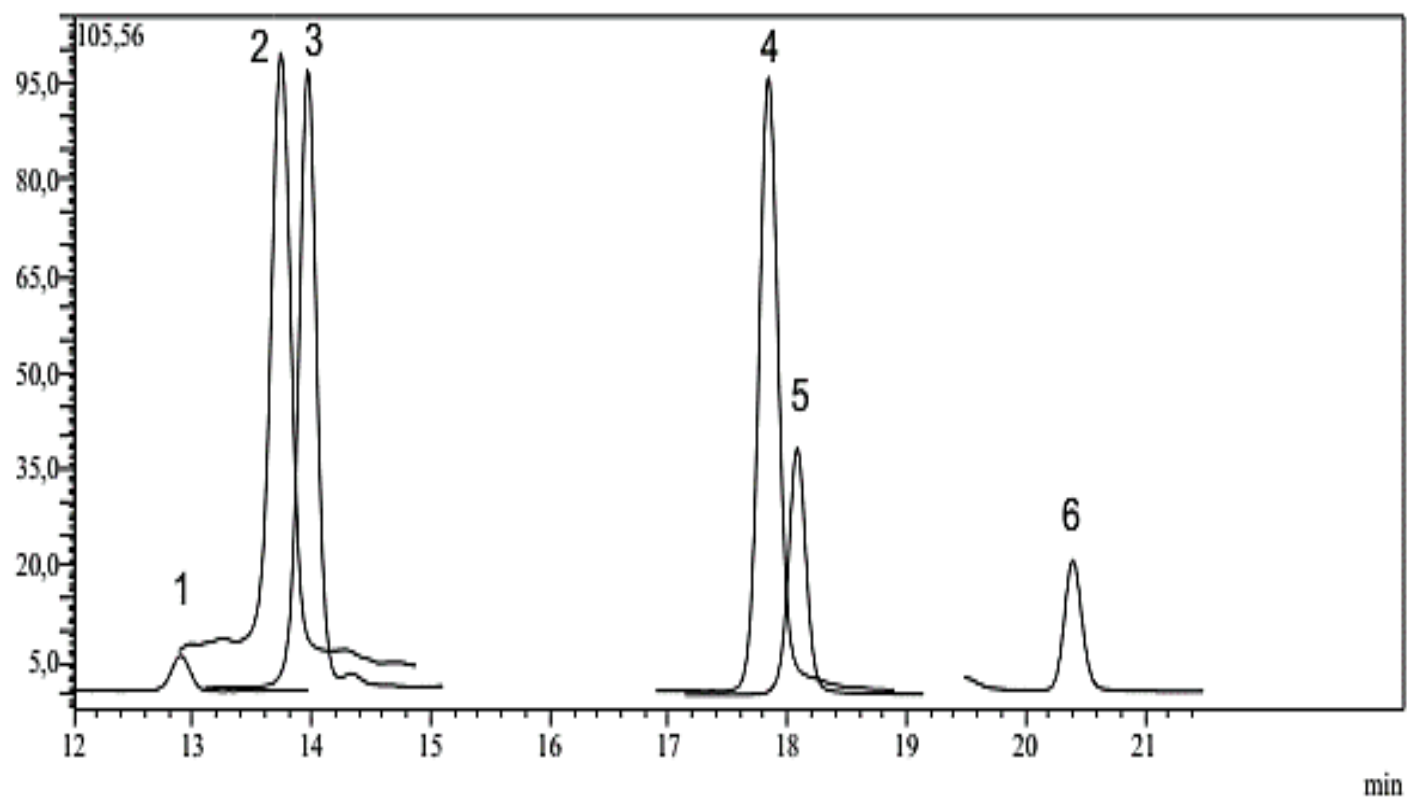

Figure 2. TIC chromatogram of fat soluble vitamin standards (1: vitamin $\mathrm{A}$ acetate (IS), 2: vitamin $\mathrm{D}_{2}, 3$ : vitamin $\mathrm{D}_{3}, 4$ : vitamin $\mathrm{K}_{2}, 5$ : vitamin $\mathrm{E}$, 6: vitamin $\mathrm{K}_{1}$ ) analysed by LC-MS/MS 
Table 1. Quantitative results of fat soluble vitamins in walnut samples by LC-MS/MS (mg analyte/kg dry fruit)

\begin{tabular}{llllll}
\hline Sample & Vitamin $\mathrm{D}_{2}$ & Vitamin $\mathrm{D}_{3}$ & Vitamin $\mathrm{K}_{2}$ & Vitamın E & Vitamin $\mathrm{K}_{1}$ \\
\hline MDE2 & 28.4 & N.D. & N.D. & 9.2 & N.D. \\
MDE5 & 19.8 & N.D. & N.D. & 15.2 & N.D. \\
MDE18 & 22.0 & N.D. & N.D. & 6.2 & N.D. \\
MDE24 & 21.2 & N.D. & N.D. & 7.6 & N.D. \\
MDE32 & 29.0 & N.D. & N.D. & 7.0 & N.D. \\
MDE39 & 24.2 & N.D. & N.D. & 13.6 & N.D. \\
MDE42 & 28.2 & N.D. & N.D. & 9.2 & N.D. \\
MDE45 & 26.8 & N.D. & N.D. & 6.8 & N.D. \\
MDE50 & 28.8 & N.D. & N.D. & 9.2 & N.D. \\
MDE56 & 21.0 & N.D. & N.D. & 6.6 & N.D. \\
MDE67 & 20.6 & N.D. & N.D. & 6.6 & N.D. \\
Chandler & 23.4 & N.D. & N.D. & 8.8 & N.D. \\
Franquette & 26.4 & N.D. & N.D. & 8.6 & N.D. \\
\hline
\end{tabular}

Being a a fat-soluble vitamin, vitamin $\mathrm{D}$ (ergocalciferol- $\mathrm{D}_{2}, \quad$ cholecalciferol- $\mathrm{D}_{3}$, alfacalcidol) helps the human body absorb phosphorus and calcium. Calcium, and phosphorus is important for building and maintaining bone strength having the right amount of vitamin $\mathrm{D}$,. Vitamin $\mathrm{D}_{2}$ was the most abundant fat soluble vitamin in all of the studied walnut samples, followed by vitamin E. Considering the fact that vitamin $\mathrm{D}_{3}$ is only found in animal-sourced foods and vitamin $D_{2}$ mainly comes from plant sources and fortified foods, it is expected walnuts do not contain vitamin $\mathrm{D}_{3}$. Being the predominant vitamin in all walnut samples, vitamin $\mathrm{D}_{2}$ content of the MDE32, MDE50, MDE2 and MDE42 genotypes (29.0, 28.8, 28.4 and $28.2 \mathrm{mg} / \mathrm{kg}$ plant, respectively) were the most abundant among the other samples. On the other hand, MDE5 and MDE67 genotypes had the lowest amount of vitamin $\mathrm{D}_{2} \quad(19.8$ and $20.6 \mathrm{mg} / \mathrm{kg}$ plant, respectively).



Figure 3. TIC chromatogram of the genotype MDE2 analysed by LC-MS/MS 
Vitamin E is a key component for strong immunity, healthy eyes and skin. MDE5 and MDE39 contained remarkable quantities of vitamin $\mathrm{E}(15.2$ and $13.6 \mathrm{mg} / \mathrm{kg}$ dry plant, respectively), while MDE18, MDE56 and MDE67 contained the lowest amount of the vitamin $(6.2,6.6$ and $6.6 \mathrm{mg} / \mathrm{kg}$ dry plant, respectively). From a general perspective, it is noteworthy that, local walnut genotypes were richer than the commercial cultivars (Chandler and Franquette) in terms of vitamins $\mathrm{D}_{2}$ and $\mathrm{E}$.

Several recent literatures mentioned some fat sluble vitamins in nuts. In a former study, the impact of roasting on vitamin contents of nuts was investigated and $\alpha$ - and $\gamma$ - tocopherol (2.1, 1.4 and $0.9 \mathrm{mg} \alpha$-tocopherol/100 $\mathrm{g}$ walnut, respectively) contents of walnut found to be decreased (Stuetz et al., 2017). In another study, tocopherol contents of seven walnut varieties from Turkey were studied. In this study $\alpha-, \gamma-$ and $\delta$-tocopherol amounts of walnuts ranged from 9.69 to $14.13,298.75$ to 470.02 and 10.06 to $25.98 \mathrm{mg} / \mathrm{kg}$ walnut, respectively (Bakkalbaş1 et al., 2014). Savage et al. evaluated the tocopherol contents of different walnut cultivars from Europa, US and New Zealand (Savage et al., 1999). They found that $\alpha-, \beta, \gamma-$ and $\delta$ tocopherol amounts ranged between 14.8-28.7, 1.0-8.2, 206.9-355.0 and 28.0-62.1 $\mu \mathrm{g} / \mathrm{g}$ oil, respectively. A recent study demonstrated that, Lake and Combe varieties of Persian walnuts contained 267.87 and $205.45 \mu \mathrm{g} / \mathrm{g}$ of $\gamma$ tocopherol, respectively (Tsao et al., 2007).
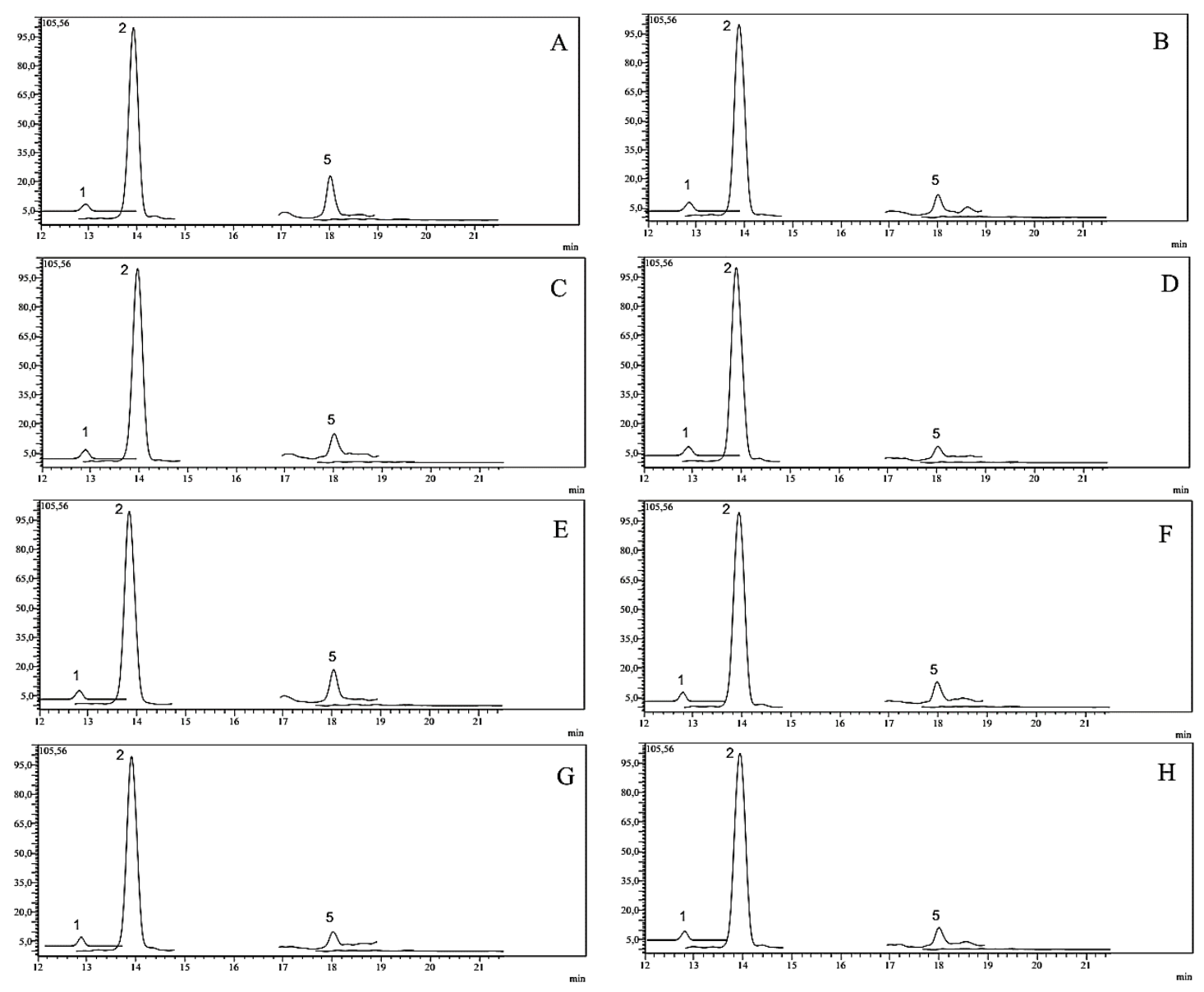

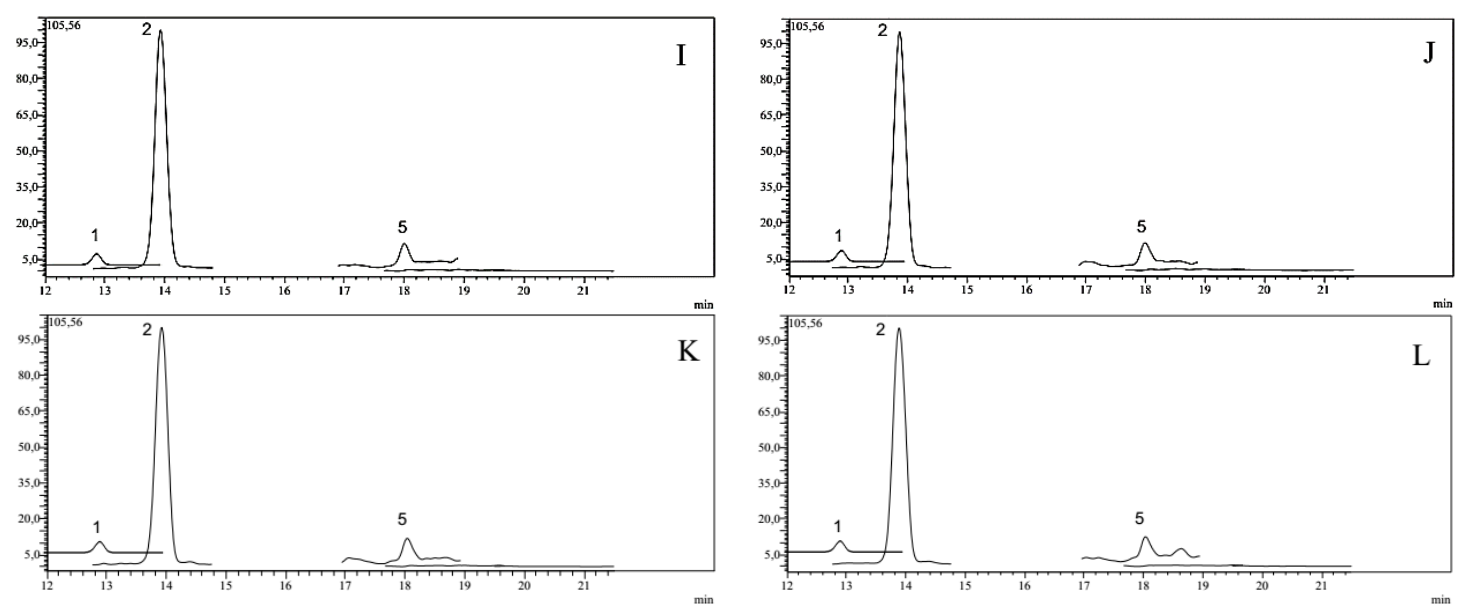

Figure 4. TIC chromatogram of the walnut samples analysed by LC-MS/MS (A: MDE 5, B: MDE 18, C: MDE 24, D:

MDE 32, E: MDE 39, F: MDE 42, G: MDE 45, H: MDE 50, I: MDE 56, J: MDE 67, K: Chandler, L: Franquette)

\section{CONCLUSION}

To conclude, in the present study a comprehensive and robust LC-MS/MS method was developed and validated for simultaneous quantitaton of fat soluble vitamins $\mathrm{D}_{2}, \mathrm{D}_{3}, \mathrm{~K}_{2}, \mathrm{E}$ and $\mathrm{K}_{1}$ in eleven walnut genotypes and two commercial walnut cultivars from the Southeast part of Turkey. According to the quantitative results of the LC-MS/MS analysis, amounts of vitamin $\mathrm{D}_{2}$ and vitamin $\mathrm{E}$ found to be quite high in the studied genoypes and commercial cultivars of walnut samples. However, other studied vitamins $\left(\mathrm{D}_{3}, \mathrm{~K}_{2}\right.$ and $\left.\mathrm{K}_{1}\right)$ were not present in any of the walnut samples. Additionally, MDE5 and MDE39 were the richest samples in terms of vitamin E. The results of the present study show that walnuts can provide valuable amounts of vitamin $D_{2}$ and vitamin E. The data confirm that of walnut genotypes and cultivars are a rich source of significant vitamins that would be very beneficial to human health. The results will be useful to know about the nutritional properties of the walnut genotypes and cultivars, may guide us in designing strategies, might contribute to breeding studies of walnut genotypes and their commercial production in future.

\section{ACKNOWLEDGEMENT}

I give my sincere thanks to Dicle University (DUBTAM) for the laboratory facilities and Prof. Dr. Mikdat Şimşek for his support in supplying the walnut samples.

\section{REFERENCES}

Abbey M, Noaks M, Belling GB, Nestel PJ, 1994. Partial Replacement of Saturated Fatty Acids with Almonds or Walnuts Lowers Total Plasma Cholesterol and Low-DensityLipoprotein Cholesterol. American Journal of Clinical Nutrition, 59:995-999.

Amaral JS, Alves MR, Seabra RM, Oliveira BPP, 2005. Vitamin E composition of walnuts (Juglans regia L.): a 3-year comparative study of different cultivars. Journal of Agricultural and Food Chemistry, 53: 54675472.

Awad AB, Fink CS, 2000. Phytosterols as anticancer dietary components: evidence and mechanism of action. Journal of Nutrition, 130: $2127-2130$. 
Bakkalbaşı E, Yılmaz ÖM, Poyrazoğlu ES, Artık N, 2014. Tocopherol contents of walnut varieties grown in Turkey and the Effect of Storage on Tocopherol Content. Journal of Food Processing and Preservation, 38: 518526.

Crews C, Hough P, Godward J, Brereton P, Lees M, Guiet S, Winkelmann W, 2005. Study of the main constituents of some authentic walnut oils. Journal of Agricultural and Food Chemistry, 53: 4853-4860.

\section{EURACHEM CITAC Guide CG4. 2004.} Quantifiying Uncertainty in Analytical Measurement, 3rd ed.; Ellison, S. L. R., Williams, A.,, Eds.; available from www.eurachem.org (Accessed 5 November 2018).

FAO. 2018. Food and Agriculture Organization of the United Nations FAOSTAT, http://www.fao.org/faostat/en/?\#data

(Accessed 16 October 2018).

Fraser GE, Sabaté J, Beeson WL, Strahan TMA, 1992. Possible Protective Effect of Nut Consumption on Risk of Coronary Heart Disease. Archives of Internal Medicine, 152: 1416-1424.

Ibarrola-Jurado N, Bulló M, Guasch-Ferré M, Ros E, Martínez-González MA, Corella D, Fiol M, Wärnberg J, Estruch R, Román P, Arós F, Vinyoles E, Serra-Majem L, Pintó X, Covas MI, Basora J, Salas-Salvadó J; PREDIMED Study Investigators, 2013. Cross-sectional assessment of nut consumption and obesity, metabolic syndrome and other cardiometabolic risk factors: the PREDIMED study. PLoS One, 8.

Martínez ML, Mattea MA, Maestri DM, 2006. Varietal and crop year effects on lipid composition of walnut (Juglans regia) genotypes. Journal of the American Oil Chemists' Society, 83: 791-796.
Rabadán A, Pardo JE, Pardo-Giménez A, ÁlvarezOrtí M, 2018. Effect of genotype and crop year on the nutritional value of walnut virgin oil and defatted flour. Science of the Total Environment, 634: 1092-1099.

Sabaté J, Fraser GE, Burke K, Knutsen SF, Bennett H, Linstead K.D, 1993. Effects of Walnuts on Serum Lipid Levels and Blood Pressure in Normal Men. The New England Journal of Medicine, 329: 603-607.

Santos J, Álvarez-Ortí M, Sena-Moreno E, Rabadán A, Pardo JE, Oliveira BPP, 2017. Effect of roasting conditions on the composition and antioxidant properties of defatted walnut flour. Journal of the Science of Food and Agriculture, 98: 1813-1820.

Stuetz W, Schlörmann W, Glei M, 2017. B-vitamins, carotenoids and a-/c-tocopherol in raw and roasted nuts. Food Chemistry, 221; 222-227.

Savage GP, Dutta PC, McNeil DL, 1999. Fatty acid and tocopherol contents and oxidative stability of walnut oils. Journal of the American Oil Chemists' Society, 76: 10591063.

Tsao R, Yang R, Kramer JKG, Hernandez M, 2007. Fatty Acid Profiles, Tocopherol Contents, and Antioxidant Activities of Heartnut (Juglans ailanthifolia Var. cordiformis) and Persian Walnut (Juglans regia L.). Journal of Agricultural and Food Chemistry, 55 (4): 1164-1169.

Yang J, Liu RH, Halim L, 2009. Antioxidant and antiproliferative activities of common edible nut seeds. LWT - Food Science and Technology, 42: 1-8. 